УДК 669.717: 669.040: 26:669. 046.55.001.57

М.В. Бабенко, к.т.н., доцент

Р. В. Волошин, магістр

Г. А. Кривошесв, студент

Дніпровський державний технічний університет, м. Кам’янське

\title{
ОБГРУНТУВАННЯ ВИБОРУ ЧИСЕЛЬНОГО МЕТОДУ ДЛЯ ВИРІШЕННЯ ЗАВДАННЯ ПЛАВЛЕННЯ, КОМБІНОВАНОГО АЛЮМОВМІСЬКОГО РОЗКИСЛЮВАЧА ЦИЛІНДРИЧНОЇ ФОРМИ, 3 ОБВАЖНЮВАЧЕМ, В ЗАХИСНІЙ ОБОЛОНЦІ
}

У цій статті представлено порівняльний аналіз чисельних методів розрахунку модельного завдання плавлення призми за несиметричних граничних умов для обтрунтування вибору чисельного методу рішення задачі плавлення, комбінованого розкислювача циліндричної форми, в захисній оболониі в розплаві $i$ за несиметричних граничних умов на міжфазній межі шлакметал. сна оболонка.

Ключові слова: чисельний метод, комбінований розкислювач циліндричної форми, захи-

This paper presents a comparative analysis of numerical calculation methods for model problem of prismmeltingunder asymmetric boundary conditions to substantiate the choice of the numerical method for solving the melting problem of a weighted combined aluminum - containing deoxidizer of cylindrical form in a protective shell in the melt and under asymmetric boundary conditions at the slag - metal interface.

Keywords: calculation method, a weighted combined aluminum - containing, protective shell.

\section{Постановка проблеми}

Одним з рішень задачі ресурсозбереження при розкислюванні сталі алюмінієм є збільшення щільності алюмінієвого зливка шляхом введення обважнювача і з одночасною ізоляцією його поверхні від дії окислювального шлаку. Раніше авторами були представлені одно і двомірні математичні моделі плавлення, комбінованого алюмовмістких розкислювача циліндричної форми, з обважнювачем, в захисній оболонці (вставка і захисна оболонка з чавуну) в розплаві і за несиметричних граничних умов на міжфазній межі шлак-метал [1].

Аналіз останніх досліджень і публікацій

У статті [2] був описаний алгоритм розрахунку плавлення цього розкислювача, а також результати обчислювальних експериментів і аналіз отриманих розрахункових даних. У цій публікації проводиться обгрунтування вибору чисельного методу для вирішення завдання плавлення, комбінованого алюмовміського розкислювача циліндричної форми обважнювачем, в захисній оболонці, для чого проводиться порівняльний аналіз методів Дюзимбера і Нікітенко при рішенні модельної задачі плавлення призми за несиметричних граничних умов.

\section{Формулювання мети дослідження}

Завдання плавлення, комбінованого алюмовміського розкислювача циліндричної форми обважнювачем, в захисній оболонці відноситься до завдань теплопровідності з рухливими межами розділу фаз. Метою статті $є$ порівняння вживаємого в розрахунках методу Дюзимбера $[3,4]$ і відомішого методу Нікітенко (метод з явним виділенням межі) $[5,6]$, який успішно застосовувався для вирішення аналогічних завдань і підтверджений численними лабораторними експериментами, приведеними в роботі [7].

\section{Виклад основного матеріалу}

Приведемо алгоритм розрахунку на основі методу Нікітенко процесу плавлення призми.

Розподіл температур в призмі описується двовимірним рівнянням теплопровідності в декартовій системі координат:

$$
c(t) \rho(t) \frac{\partial t(x, y, \tau)}{\partial \tau}=\frac{\partial}{\partial x}\left[\lambda(t) \frac{\partial t(x, y, \tau)}{\partial x}\right]+\frac{\partial}{\partial y}\left[\lambda(t) \frac{\partial t(x, y, \tau)}{\partial y}\right],
$$


де $t$ - температура, ${ }^{\circ} \mathrm{C} ; \lambda-$ коефіцієнт теплопровідності; $\rho-$ щільність; $c-$ теплоємність призми.

Граничні умови. Уздовж осей симетрії призми тепловий потік дорівнює 0, тобто:

$$
\frac{\partial t(0, y, \tau)}{\partial x}=0, \quad \frac{\partial t(x, 0, \tau)}{\partial y}=0 .
$$

На бічних поверхнях призми в період прогрівання відбувається конвективний теплообмін з розплавом:

$$
\begin{aligned}
& -\lambda(t, x, y) \frac{\partial(x, y, \tau)}{\partial x}=\alpha_{x}\left(t(x, y, \tau)-t_{\varkappa}\right), \\
& -\lambda(t, x, y) \frac{\partial(x, y, \tau)}{\partial y}=\alpha_{y}\left(t(x, y, \tau)-t_{\varkappa}\right) .
\end{aligned}
$$

Граничні умови в період плавлення представимо в наступному виді:

$$
\alpha_{i}\left(t(x, y, \tau)-t_{ж}\right)-\lambda \frac{\partial t(P)}{\partial \bar{n}}=-\rho Q W(P) ;-t(P)=t_{\text {пл }} .
$$

Початковий розподіл температури в призмі приймається рівномірним:

$$
t(x, y, 0)=20^{\circ} \mathrm{C} \text {. }
$$

Для чисельного вирішення завдання (1)-(6) будується різницева сітка $x_{i}=i \cdot \Delta x, y_{m}=$ $m \cdot \Delta y$. Прямі $x_{i}$ і $y_{m}$ назвемо координатами, позначимо через $x_{m}^{n}$ абсцису точки, що лежить на перетині координатної прямої $y_{m}$ і межі розділу фаз, через $y_{m}^{n}-$ іï ординату, і через $y_{i}^{n}$ - ординату точки, що лежить на перетині координатної прямої $x_{i}$ і межі розділу фаз, а через $x_{i}^{n}-$ iï абсцису.

Положення межі розділу фаз може бути визначене з будь-якою наперед заданою точністю за допомогою завдання координат рухливих вузлових точок.

Зміна положення межі розділу фаз визначається таким чином. У рівнянні (5) $\frac{d z}{d \tau}-$ швидкість руху межі уздовж нормалі і їі доцільно розкласти на дві складові. Тепловий потік $\frac{\partial t}{\partial \bar{n}}$ також проектуємо на осі OX і OY. Рівняння (5) в цьому випадку матиме вигляд:

$$
\begin{aligned}
\rho Q^{\frac{d z x}{d \tau}} & =\alpha\left(t_{n n}-t_{\varkappa}\right) \cos (v, x)+\lambda \frac{\partial}{\partial x} ; \\
\rho Q^{\frac{d z y}{d \tau}} & =\alpha\left(t_{n n}-t_{\varkappa}\right) \cos (v, y)+\lambda \frac{\partial}{\partial y},
\end{aligned}
$$

де $z_{x}$ i $z_{y}$ - проекції швидкості руху межі уздовж нормалі на осі ОХ і ОY відповідно.

Розглянемо цю систему рівнянь для точки 1 (малюнок $1, a$ ):

$$
\begin{aligned}
& \rho Q \frac{x_{i}^{n+1}-x_{i}^{n}}{\Delta \tau}=\alpha\left(t_{n л}-t_{\varkappa}\right) \cos (v, x)+\frac{\lambda\left(t_{n л}-t^{\prime}{ }_{i-1}\right)}{\Delta x} \\
& \rho Q \frac{y_{i}^{n+1}-y_{i}^{n}}{\Delta \tau}=\alpha\left(t_{n л}-t_{\varkappa}\right) \cos (v, y)+\frac{\lambda\left(t_{n \pi}-t_{i, m}^{n}\right)}{y_{i}^{n}-(m-1) \cdot \Delta y} .
\end{aligned}
$$

цію:

Оскільки температура невідома, то для іiї визначення застосовуємо лінійну апроксима-

$$
t_{i-1}^{\prime}=\frac{y_{i}^{n}-(m-1) \cdot \Delta y}{y_{i-1}^{n}-y_{i}^{n}}\left(t_{n \pi}-t_{i-1, m}^{n}\right)+t_{i-1, m}^{n} .
$$


Якщо точка, в якій обчислюється температура, має в якості суміжної не граничну вузлову точку 1 (малюнок $1, \sigma)$, тоді формула для визначення невідомої температури матиме вигляд:

$$
t_{i-1}^{\prime}=\frac{y_{i}^{n}-(m-1) \cdot \Delta y}{y_{i-1}^{n}-y_{i}^{n}}\left(t_{i-1, m+1}^{n}-t_{i-1, m}^{n}\right)+t_{i-1, m}^{n} .
$$

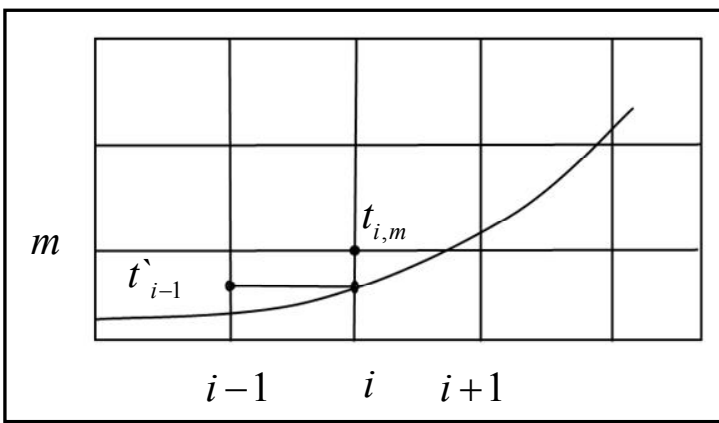

$a$

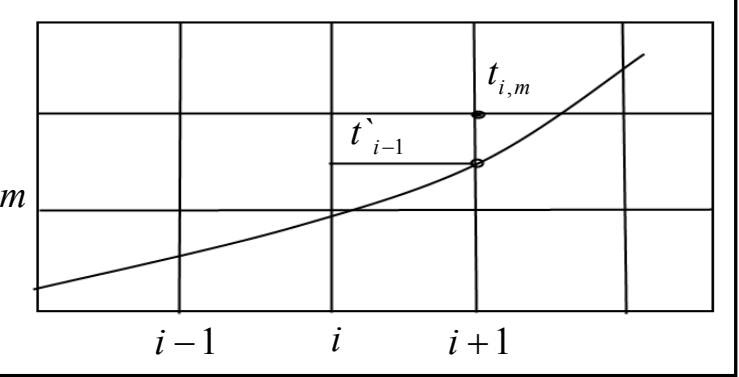

$\sigma$

Рuc. 1. Схема до розрахунку температури в граничних точках

Для точок, що лежать на перетині координатних прямих і межі розділу фаз, проводяться аналогічні міркування.

Вирішуючи послідовно систему (9)-(10) для усіх вузлових граничних точок, знаходимо нові координати граничних вузлових точок. Оскільки знову отримані координати граничних вузлових точок, як правило, не лежать на координатних прямих, то для визначення положення межі треба з'єднати ці точки прямими. Перетин цих прямих з координатними прямими дає нові вузлові граничні точки. Таким чином, розраховується положення межі на $n+1$ тимчасовому шарі.

Як правило, напрям нормалі до межі не заданий. Тому значення кута в точці $\left(x_{0}, y_{0}\right)$ знаходиться таким чином. Через дві точки, які знаходяться ліворуч і праворуч від точки $\left(x_{0}, y_{\mathrm{o}}\right) \mathrm{i}$ що мають, координати $\left(x_{1}, y_{1}\right)$ i $\left(x_{2}, y_{2}\right)$, проведемо пряму. Кут, який складає перпендикуляр до цієї прямої з віссю ОY, $€$ кут (, на який необхідно повернути систему координат. (Поворот осей потрібний для усунення помилки в обчисленні напряму нормалі). У новій системі координат обчислюємо координати точок $\left(x_{0}, y_{\mathrm{o}}\right),\left(x_{1}, y_{1}\right),\left(x_{2}, y_{2}\right)$ :

і напрям нормалі:

$$
\begin{array}{ll}
{ }^{*}=x_{o} \cdot \cos \varphi+y_{o} \cdot \sin \varphi & \stackrel{*}{y_{o}}=-x_{o} \cdot \sin \varphi+y_{o} \cdot \cos \varphi \\
{ }^{*}=x_{1} \cdot \cos \varphi+y_{1} \cdot \sin \varphi & { }^{*}=-x_{1} \cdot \sin \varphi+y_{1} \cdot \cos \varphi \\
x_{1}=x_{1} & \stackrel{*}{*}+y_{2}=-x_{2} \cdot \sin \varphi+y_{2} \cdot \cos \varphi
\end{array}
$$

$$
\operatorname{tg}^{*}(v, x)=\frac{\left(\begin{array}{c}
* \\
x_{0}-x_{1}
\end{array}\right)\left(\begin{array}{c}
* \\
x_{0}-x_{2}
\end{array}\right)\left(\begin{array}{c}
* \\
x_{2}-x_{1}
\end{array}\right)}{\left(\begin{array}{c}
* \\
y_{0}-y_{1}
\end{array}\right)\left(\begin{array}{c}
* \\
x_{0}-x_{2}
\end{array}\right)^{2}+\left(\begin{array}{c}
* \\
y_{2}-y_{0}
\end{array}\right)\left(\begin{array}{l}
* \\
x_{0}-x_{1}
\end{array}\right)^{2}} .
$$

Різниця між напрямом нормалі в перетвореній системі координат і кутом повороту осей $\epsilon$ напрям нормалі в початковій системі координат. При $x_{1}=x_{0}$ i $x_{2}=x_{0}$ або $y_{1}=y_{0} \mathrm{i} y_{2}=y_{0}$ напрям нормалі в початковій системі координат обчислюється за формулою: 


$$
\operatorname{tg}(v, x)=\frac{x_{1}-x_{2}}{y_{2}-y_{1}}
$$

Для обчислення $\cos (v, \mathrm{x})$ використовуємо формулу:

$$
\frac{1}{\cos ^{2}(v)}=1+\operatorname{tg}^{2}(v, x) \text {. }
$$

Косинус кута нормалі з віссю ОY обчислюється за формулою:

$$
\cos (v, y)=\sqrt{1-\cos ^{2}(v, x)} .
$$

Перейдемо до визначення наближених значень температур на $n+1$ тимчасовому шарі. У точках, що належать сукупності внутрішніх вузлових точок і складних граничних вузлових точок, що не мають, значення температур визначаються 3 різницевого рівняння теплопровідності в явній формі. Для точок, що мають суміжні граничні точки, застосовується різницеве рівняння теплопровідності в неявній формі. Комбінація явної і неявної схеми потрібна 3 міркування стійкості, т. до. відстань від граничної точки до вузлової може бути набагато менше кроку просторового розбиття. Якщо користуватися тільки явною схемою, то в цьому випадку, 3 міркування стійкості, необхідно враховувати крок за часом, що значно збільшує час рахунку.

Значення температур у внутрішніх вузлових точках обчислюється за формулою:

$$
\begin{gathered}
t_{i, m}^{n+1}=\left[1-\frac{\alpha \cdot \Delta \tau \cdot \lambda}{\rho \cdot c}\left(\frac{1}{\Delta x^{2}}+\frac{1}{\Delta y^{2}}\right)\right] t_{i, m}^{n}+ \\
+\frac{\Delta \tau \cdot \lambda}{\rho \cdot c \cdot \Delta x^{2}}\left(t_{i+1, m}^{n}-t_{i-1, m}^{n}\right)+\frac{\Delta \tau \cdot \lambda}{\rho \cdot c \cdot \Delta y^{2}}\left(t_{i, m+1}^{n}-t_{i, m-1}^{n}\right) .
\end{gathered}
$$

Значення температур у вузлових точках, суміжних з граничними, обчислюється за формулою:

$$
t_{i, m}^{n+1}=\frac{\frac{\lambda \cdot \Delta \tau}{\rho \cdot c \cdot \Delta x}\left(\frac{t_{n \pi}}{h_{x}}-\frac{t_{i-1, m}^{n+1}}{\Delta x}\right)+t_{i, m}^{n+1 / 2}}{1+\frac{\lambda \cdot \Delta \tau}{\rho \cdot c \cdot \Delta x}\left(\frac{1}{h_{x}}+\frac{1}{\Delta x}\right)},
$$

де $h_{x}$ - відстань між граничною і вузловою точками.

Якщо по напряму у точка 3 координатами $(i, m)$ не має суміжних граничних точок, то:

$$
t_{i, m}^{n+1 / 2}=\frac{\lambda \cdot \Delta \tau\left(t_{i, m+1}^{n}+t_{i, m-1}^{n}-2 t_{i, m}^{n}\right)}{\rho \cdot c \cdot \Delta y^{2}}
$$

якщо має, то:

$$
t_{i, m}^{n+1 / 2}=\frac{\frac{\lambda \cdot \Delta \tau}{\rho \cdot c \cdot \Delta y}\left(\frac{t_{n л}}{h_{y}}-\frac{t_{i, m-1}^{n}}{\Delta y}\right)+t_{i, m}^{n}}{1+\frac{\lambda \cdot \Delta \tau}{\rho \cdot c \cdot \Delta y}\left(\frac{1}{h_{y}}+\frac{1}{\Delta y}\right)},
$$

де $h_{y}$ — відстань між граничною точкою і внутрішньою вузловою точкою.

Для точок, які при переході від одного тимчасового шару до іншого опинилися в іншій фазі системи, значення температур визначається з урахуванням наступного. На ділянці прямої між двома вузловими точками, суміжними по відношенню до цієї точки, зміна температури можна без збільшення порядку погрішності обчислень вважати лінійним. Відповідно до цього запишуться рівняння, які визначають значення температур в точці, суміжній з граничною вузловою точкою, що рухається уздовж осей ОХ і ОY:

$$
t_{i, m}^{n+1}=t_{n л}-\frac{x_{m}^{n+1}-i \cdot \Delta x}{x_{m}^{n+1}-(i-1) \cdot \Delta x}\left(t_{n л}-t_{i-1, m}^{n}\right)
$$




$$
t_{i, m}^{n+1}=t_{n л}-\frac{y_{i}^{n+1}-m \cdot \Delta y}{y_{i}^{n+1}-(m-1) \cdot \Delta y}\left(t_{n л}-t_{i, m-1}^{n}\right) .
$$

Якщо точка $(i, m)$ має в якості суміжних граничні вузлові точки по двох напрямах, тоді температуру в цій точці, вичислену по формулах (22)-(23), необхідно усереднювати.

Для порівняння методу Дюзимбера і Нікітенко проведені розрахунки тривалості плавлення осісиметричної призми з характерним розміром $Z_{0}=0,05$ м і наступними теплофізичними характеристиками : температура плавлення $t_{\text {пл }}=1500{ }^{\circ} \mathrm{C}$, теплоємність $c=700$ Дж/(кг $\left.{ }^{\circ} \mathrm{C}\right)$, щільність $\rho=7800$ кг $/ \mathrm{M}^{3}$ коефіцієнт теплопровідності $\lambda=30 \mathrm{BT} /\left({ }^{\circ}{ }^{\circ} \mathrm{C}\right)$, питома теплота плавлення $Q=250000$ Дж/кг. Температура розплаву прийнята постійною і дорівнює $1600{ }^{\circ} \mathrm{C}$. Для отримання несиметричних граничних умов коефіцієнти тепловіддачі від розплаву до поверхні призми дорівнюють $\alpha_{1}=2000 \mathrm{BT} /\left(\mathrm{M}^{2} \cdot{ }^{\circ} \mathrm{C}\right)$ і $\alpha_{2}=10000 \mathrm{BT} /\left(\mathrm{M}^{2} \cdot{ }^{\circ} \mathrm{C}\right)$.

Результати розрахунків приведені в таблиці 1.

\section{Таблиия 1. Порівняння методів Дюзимбера і Нікітенко}

\begin{tabular}{|c|c|c|c|}
\hline Кількість розбиття, М & $\begin{array}{c}\text { Час плавлення по ме- } \\
\text { тоду Дюзимбера, сек. }\end{array}$ & $\begin{array}{c}\text { Час плавлення по ме- } \\
\text { тоду Никитенко, сек. }\end{array}$ & \% відхилення \\
\hline 10 & 297 & 328 & 9,45 \\
\hline 20 & 333 & 359 & 7,24 \\
\hline 30 & 346 & 368 & 5,98 \\
\hline 40 & 352 & 370 & 4,86 \\
\hline 50 & 356 & 372 & 4,30 \\
\hline 60 & 359 & 374 & 3,01 \\
\hline 70 & 361 & 376 & 3,98 \\
\hline 80 & 362 & 377 & 3,97 \\
\hline 90 & 363 & 378 & 3,96 \\
\hline 100 & 364 & 379 & \\
\hline
\end{tabular}

\section{Висновки}

3 таблиці видно, що розбіжність результатів розрахунку не перевищує 10 відсотків і у міру згущування різницевої сітки значно зменшується. Таким чином, адекватність розроблених алгоритмів і результатів розрахунку плавлення, комбінованого алюмовміського розкислювача циліндричної форми, на основі методу Дюзимбера $[2,3]$ підтверджується хорошим збігом результатів розрахунку модельного завдання плавлення призми за несиметричних граничних умов методами Нікітенко і Дюзимбера, а останній має набагато простіший алгоритм.

\section{Список використаної літератури}

1.Р.В. Волошин, М.В. Бабенко. Математическая модель плавления утяжеленного комбинированного алюмосодержащего раскислителя цилиндрической формы в защитной оболочке // Математичне моделювання. - 2015. - № 1(32). - С. 33-35.

2.P.В. Волошин, М.В. Бабенко, О.А. Жульковский, И.И. Жульковская, Я.А. Дегтяренко. Алгоритм расчета плавления утяжеленного комбинированного алюмосодержащего раскислителя цилиндрической формы в защитной оболочке // Математичне моделювання. 2016. - № 2(35). - С. 39-42.

3.Павлюченков И.А. Численное моделирование (на основе метода Дюзимбера) процессов плавления тел в расплаве // Математичне моделювання. - 1997. - № 2 С. 37-43.

4.Бабенко М.В. Алгоритм расчета (на основе метода Дюзимбера) двухмерной задачи плавления цилиндра в расплаве / М.В. Бабенко, И.А. Павлюченков // Металургійна теплотехніка: 3б, наук. Праць Національної металургійної академії України. - Дніпропетровськ: ПП Грек О.С., 2006. C. 3-7. 
5.Никитенко Н.И. Сопряженные и обратные задачи тепломассопереноса. - Киев: Наукова думка, 1988. -240 с.

6.Никитенко Н.И., Снежкин Ю.Ф., Сороковая Н.Н., Кольчик Ю.Н. Молекулярно-радиационная теория и методы расчета тепло- и массообмена. - К.: Наукова думка, 2014, -743 с.

7.Павлюченков И.А. Теория и технология плавления материалов в жидкой стали: Дис. докт. техн. наук. - Днепродзержинск, 1995. - 330 с. 